\title{
WEIGHTED COMPOSITION OPERATOR ON TWO-DIMENSIONAL LORENTZ SPACES
}

\section{René Erlín CAstillo And Héctor CAmilo Chaparro}

Abstract. The boundedness, compactness, closed range and invertibility of the weighted composition operator on two-dimensional Lorentz spaces are characterized.

Mathematics subject classification (2010): Primary 47B33, 47B38, Secondary 46E30.

Keywords and phrases: Multiplication operator, composition operator, multidimensional rearrangement, Lorentz spaces.

\section{REFERENCES}

[1] M. B. Abrahamese, Lecture notes in Math, Multiplication operators, vol. 693, Springer Verlag, New York, 1978.

[2] M. A. ARiÑo AND B. MuCKenhoupt, Maximal functions on classical Lorentz spaces and Hardy's inequality with weights for nonincreasing functions, Transactions of the American Mathematical Society 320, 2 (1990), 727-735.

[3] S. C. ARora, G. DATT, AND S. Verma, Multiplication operators on Lorentz spaces, Indian Journal of Mathematics 48, 3 (2006), 317-329.

[4] S. C. Arora, G. Datt, And S. Verma, Composition operators on Lorentz spaces, Bulletin of the Australian Mathematical Society 76, 2 (2007), 205-214.

[5] A. AXLER, Multiplication operators on Bergman space, Reine Angew Math 33, 2 (1982), 26-44.

[6] S. BARZA, Weighted multidimensional integral inequalities and applications, $\mathrm{Ph} . \mathrm{D}$. thesis, Luleå University of Technology, 1999.

[7] S. BARZA, L. E. PERSSON, AND J. SORIA, Sharp weighted multidimensional integral inequalities for monotone functions, Mathematische Nachrichten 210, 1 (2000), 43-58.

[8] S. Barza, L. E. Persson, AND J. Soria, Multidimensional rearrangement and Lorentz spaces, Acta Mathematica Hungarica 104, 3 (2004), 203-224.

[9] S. Barza, L .E. Persson, And V. Stepanov, On weighted multidimensional embeddings for monotone functions, Mathematica Scandinavica 88, 2 (2001), 303-319.

[10] C. Bennett And R. Sharpley, Interpolation of operators, vol. 129, Academic Press Inc, New York, 1988.

[11] A. P. BLOZINS KI, Multivariate rearrangements and Banach function spaces with mixed norms, Transactions of the American Mathematical Society 263, 1 (1981), 149-167.

[12] M. Carro, L. Pick, J. Soria, And V. D. Stepanov, On embeddings between classical Lorentz spaces, Mathematical Inequalities and Applications 4 (2001), 397-428.

[13] M. CARRo AND J. SORIA, Weighted Lorentz spaces and the Hardy operator, Journal of functional analysis 112, 2 (1993), 480-494.

[14] R. E. Castillo, H. C. Chaparro, and J. C. Ramos Fernández, Orlicz-Lorentz Spaces and their Composition Operators, Proyecciones (Antofagasta) 34, 1 (2015), 85-105.

[15] R. E. Castillo, H. C. Chaparro, and J. C. Ramos Fernández, Orlicz-Lorentz Spaces and their Multiplication Operators, Hacet. J. Math. Stat. 44, 5 (2015), 991-1009.

[16] R. E. Castillo, D. D. Clahane, J. Farías López, and J. C. Ramos Fernández, Composition operators from logarithmic Bloch spaces to weighted Bloch spaces, Applied Mathematics and Computation 219, 12 (2013), 6692-6706. 
[17] R. E. Castillo, J. C. Ramos Fernández, and E. M. Rojas, A New Essential Norm Estimate of Composition Operators from Weighted Bloch Space into-Bloch Spaces, Journal of Function Spaces and Applications 2013 (2013).

[18] R. E. Castillo, R. LeÓn, And E. Trousselot, Multiplication operator on $L_{(p, q)}$ spaces, Panamer. Math. J. 19, 1 (2009), 37-44.

[19] R. E. Castillo, F. A. Vallejo Narváez, and J. C. Ramos Fernández, Multiplication and Composition Operators on Weak $L_{p}$ spaces, Bulletin of the Malaysian Mathematical Sciences Society 38, 3 (2015), 927-973.

[20] R. E. CAStillo AND H. Rafeiro, An Introductory Course in Lebesgue Spaces, Springer International Publishing, New York, 2016.

[21] R. E. Castillo, H. Rafeiro, J. C. Ramos Fernández, and M. Salas-Brown, Multiplication operator on Köthe spaces: measure of non-compactness and closed range, Submitted (2016).

[22] Y. Cui, H. Hudzik, R. Kumar, And L. Maligranda, Composition operators in Orlicz spaces, Journal of the Australian Mathematical Society 76, 2 (2004), 189-206.

[23] R. G. Douglas, Banach algebra techniques in operator theory, vol. 179, Springer Science \& Business Media, 2012.

[24] L. Grafakos, Classical Fourier Analysis, second ed., vol. 249, Springer, New York, 2008.

[25] P. R. Halmos, A Hilbert space problem book, vol. 19, Springer Science \& Business Media, 2012.

[26] G. H. HaRdy and J. E. LitTlewood, A maximal theorem with function-theoretic applications, Acta Mathematica 54, 1 (1930), 81-116.

[27] R. Hunt, On L( $p, q)$ spaces, L'Enseignment Math 12, 2 (1966), 249-276.

[28] B. S. Komal And S. Gupta, Multiplication operators between Orlicz spaces, Integral Equations and Operator Theory 41 (2001), 324-330.

[29] B. S. Komal And R. S. Pathania, Composition operators on a space of operators, Indian J. Math. 33 (1991), 11-17.

[30] A. KUMAR, Fredholm composition operators, Proceedings of the American Mathematical Society 79, 2 (1980), 233-236.

[31] E. H. Lieb AND M. Loss, Analysis, volume 14 of graduate studies in mathematics, American Mathematical Society, Providence, RI, 4 (2001).

[32] G. G. LorentZ, Some new function spaces, Ann. Math. 51, 1 (1950), 37-55.

[33] G. G. Lorentz, On the theory of spaces $\lambda$, Pacific J. Math. 1 (1951), 411-429.

[34] E. SAWYER, Boundedness of classical operators on classical Lorentz spaces, Studia Mathematica 96, 2 (1990), 145-158.

[35] R. K. Singh AND A. Kumar, Multiplication and composition operators with closed ranges, Bull. Aust. Math. Soc. 16 (1977), 247-252.

[36] V. D. Stepanov, The weighted Hardy's inequality for nonincreasing functions, Transactions of the American Mathematical Society 338, 1 (1993), 173-186.

[37] H. TAKAGI, Fredholm weighted composition operators, Integral Equations and Operator Theory 16 (1993).

[38] H. TaKagi And K. Yokouchi, Multiplication and Composition Operators between Two $L_{p}$-Spaces, Function Spaces: Proceedings of the Third Conference on Function Spaces, May 19-23, 1998, Southern Illinois University at Edwardsville, vol. 232, American Mathematical Soc., 1999, p. 321. 